\title{
Numerical Analysis of Reinforcement Structure Stability Based on the Stress State of Geogrid
}

\author{
Xiaosong Tang1,2, Yongfu Wang'2, Zhixiang Liu ${ }^{3}$ \\ ${ }^{1}$ China Merchants Chongqing Communications Technology Research \& Design Institute Co. Ltd., Chongqing, China \\ ${ }^{2}$ Engineering and Technology Research Center of Geological Hazard Prevention and Treatment, Chongqing, China \\ ${ }^{3}$ Civil King Information Technology Company Limited, Beijing, China \\ Email:hnm97@163.com
}

How to cite this paper: Tang, X.S., Wang, Y.F. and Liu, Z.X. (2018) Numerical Analysis of Reinforcement Structure Stability Based on the Stress State of Geogrid. World Journal of Engineering and Technology, 6, 383-392.

https://doi.org/10.4236/wjet.2018.62023

Received: April 3, 2018

Accepted: May 15, 2018

Published: May 18, 2018

Copyright $\odot 2018$ by authors and Scientific Research Publishing Inc. This work is licensed under the Creative Commons Attribution International License (CC BY 4.0).

http://creativecommons.org/licenses/by/4.0/

\begin{abstract}
The reinforcement effect of geogrids is exerted through the fixing and occlusion with the surrounding soil to ensure the stability of reinforced structure. Based on the friction reinforced mechanism, the geogrids play the role of anti-shear and anti-pulling. So the indexes of interface strength identified by shear and tensile tests are usually used to conduct the stability analysis of reinforced structure. At present, the same indexes of interface strength are adopted in the stability analysis of reinforced structure, where only one of the anti-shearing action or anti-pulling effect of geogrid is considered, which is separated from the practical stress state of geogrids and has certain limitation. To solve the problem, the paper adjusts the interface indexes of geogrids based on the potential sliding surface and the stress state of geogrids when the failure happens. So the method of stability analysis is concluded where cyclic iterative analysis is carried out till the interface characters of geogrids and the unstable mode of the whole structure are the same. The calculation examples of reinforced soil slope in the paper shows that the method can fully reflect the reinforcement of geogrids and can complete the adoption of numerical method in the stability analysis of reinforcement structure.
\end{abstract}

\section{Keywords}

Interface Characters, Tensile-Shear Combination, Geogrid, FEM Reduction, Reinforcement Structure

\section{Introduction}

The reinforcement structure of geogrids is widely used in various soil filling engineering due to its feasibility and low price. The height and the size of the engineering are increasing continuously with the development of its stability analysis 
method [1] [2] [3] [4]. In the researches of the stability of reinforcement structure, the interface features of geogrids are the important and difficult points. When the numerical analysis is adopted, the quantitative analysis of the stability for the reinforced structure can be conducted only if the interface strength of geogrids is identified. At present, the studies on the interface features of geogrids between filling soil are based on the reinforced theories of friction, where the indoors experiment is most common, including direct shear and tensile experiments. The interface strength, deformation characters, interface stress and relative curve of strain are different to a large extent because of the difference in experimental mechanisms through these two methods. The researchers from different countries have studied the reasonableness and adoption of the methods, but the final conclusion has not been reached. So new ideas and methods are needed to solve the problem.

The paper first studies the failure mode of reinforcement structure with geogrids through FEM strength reduction. Whether it is shear or tensile function happens on the geogrids interface is identified through the potential sliding surface, so as to ensure the interface of geogrids can exert its function reasonably. Based on the above researches, the paper establishes iterative algorithm corresponding to the stability analysis of reinforcement structure of geogrids. The method can work out the safety factor and search the potential sliding surface through FEM strength reduction. Based on the mode of potential sliding surface and the stress state on the geogrids, the interface parameters can be adjusted to form cyclic iterative analysis till the interface features are the same with the unstable failure mode of the whole structure, where the iterative analysis is completed.

\section{Studies on the Unstable Failure Mode and Stress State of Geogrids Interface}

The reinforcement structure is composed of geogrids and filling soil, whose properties are totally different. The mode of unstable failure is decided by the soil strength, mechanic parameters of geogrids, geometric states of reinforcement structure and so on. FEM strength reduction can conduct stability analysis of the reinforcement structure with geogrids [5] [6]. Three unstable failure modes can be worked out through different combination of parameters: inner unstable failure; inner and outer mixed unstable failure and outer unstable failure.

The unstable failure modes of reinforcement structure with geogrids from Figure 1 to Figure 3 show that the stress state of geogrids interface includes three forms due to the different location of geogrids and potential sliding surface:

Form 1: the geogrids tend to be pulled out when they are located behind the potential sliding surface. The geogrids interface exerts tensile force so the indexes of interface strength obtained through tensile experiments are more reasonable to be used in the simulation. 


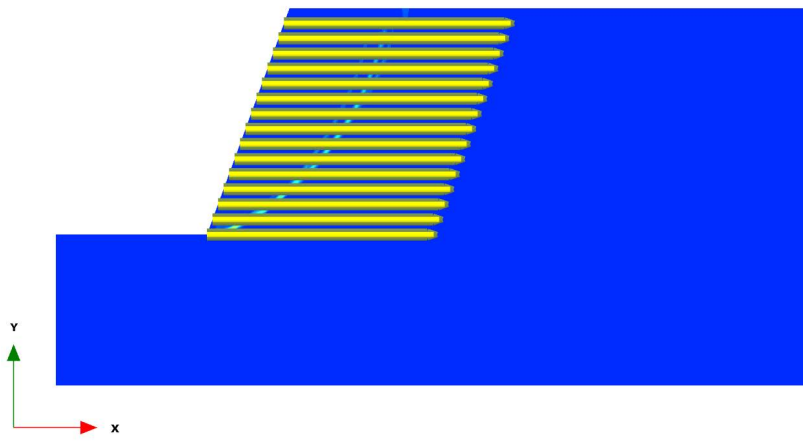

(a)

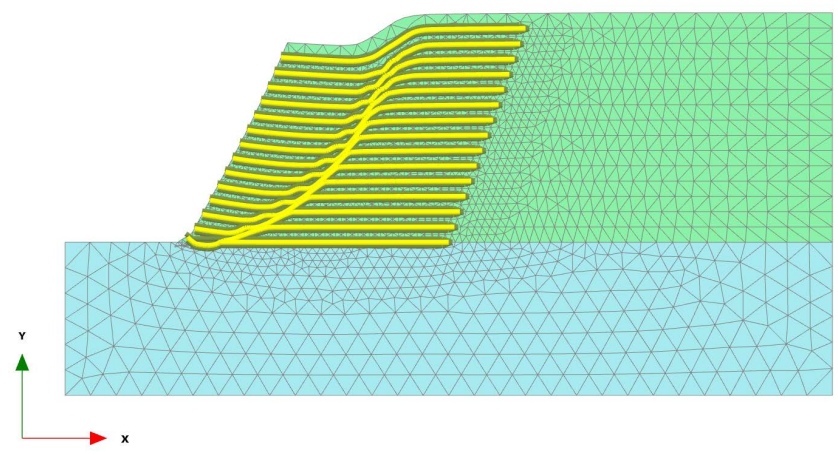

(b)

Figure 1. Inner unstable failure mode. (a) Potential sliding surface according to total strain $\gamma_{\dot{S}}$ (b) Deformation characters according to deformed mesh.

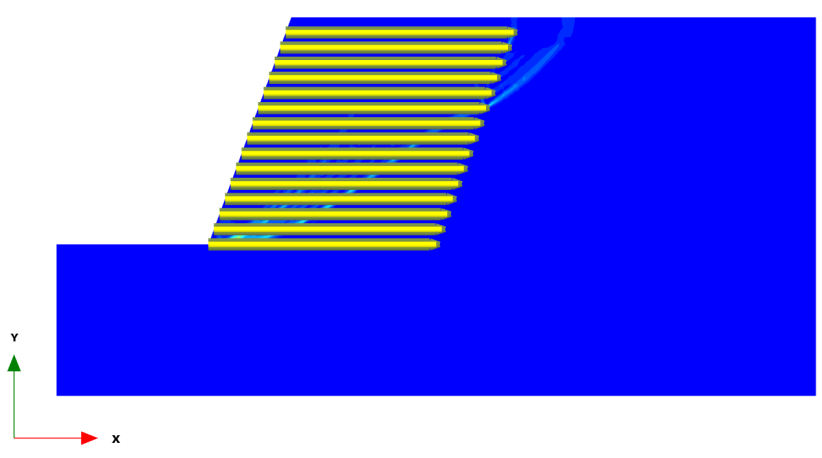

(a)

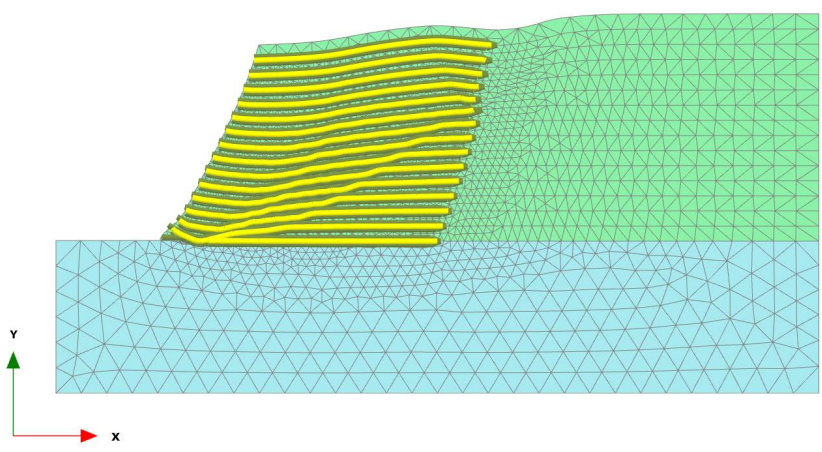

(b)

Figure 2. Inner and outer mixed unstable failure mode. (a) Potential sliding surface displayed according to the total strain $\gamma_{\mathcal{S}}$ (b) Deformation characters according to deformed mesh.

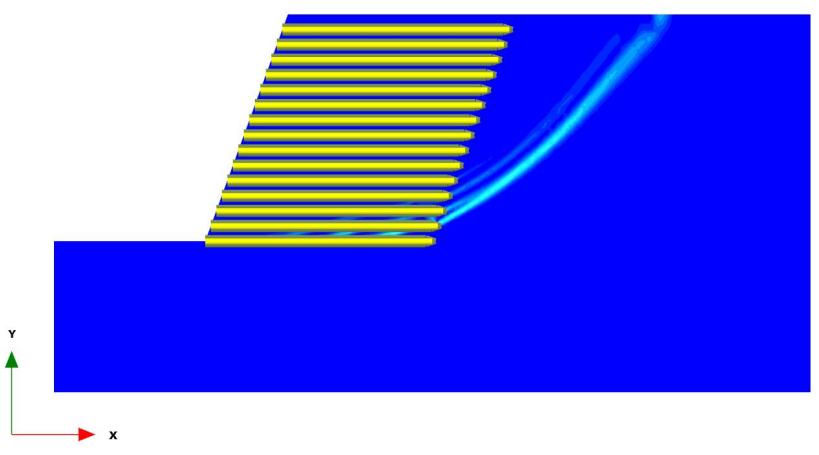

(a)

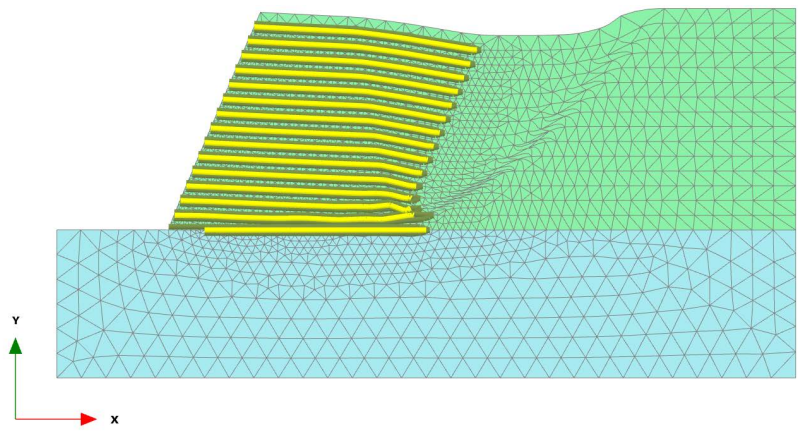

(b)

Figure 3. Outer unstable failure mode. (a) Potential sliding surface displayed according to the total strain $\gamma_{\dot{S}}$ (b) Deformation characters according to deformed mesh.

Form 2: when the geogrids are parallel to the potential sliding surface, shear sliding happens on the geogrid interface in the lower part of the reinforcement structure if outer failure appears. The geogrids interface exerts shear force so the indexes of interface strength obtained through shear experiments are more reasonable to be used in the simulation.

Form 3: when the geogrids are inside the sliding surface, through the fixation 
and occlusion of the surrounding soil, the shear slip of the geogrid interface is prevented. The interface of geogrids exerts shear force, so the indexes of interface strength obtained through shear experiments are more reasonable to be used in the simulation.

The above analysis show that the interface exerts shear or tensile or both under different stress states, so only considering one of the anti-shearing action or anti-pulling effect of geogrid is limited in the stability analysis of reinforced structure.

\section{The Analysis of the Suggested Values of Geogrids Interface Strength}

At present, interface parameters are used in most countries or institutes to reflect the interactive effects of geogrids interface between the surrounding soil [7] [8] [9] [10] [11]. Although interfaces parameters are called differently: interface friction factor, pseudo-friction factor and resistance coefficient, the specific calculation methods are the same, which is interface parameters $=\tan \varphi_{G S} \tan \varphi$, where $\varphi_{G S}$ is interface friction angle and $\varphi_{S}$ is the inner friction angle of filling soil. According to the suggested values from different countries' codes (shown in Table 1), the interface strength index $\varphi_{G S}$ can be worked out when $\varphi_{S}$ is known.

Table 1 is the suggested values for the interface strength of geogrids. At present, most interface parameters under pullout condition is larger than that under shear conditions, so using the same interface strength indexes and only considering shear or tensile effects of the geogrids are not reasonable.

\section{Iterative Analysis for the Stability Analysis of Reinforcement Structure Based on the Stress State of Geogrids}

To make the stress state of geogrids interface and the unstable failure mode of the reinforcement structure identical, the paper establishes the iterative analysis for the stability of reinforcement structure of geogrids. The analytic process is shown in Figure 4.

Under the initial condition, the geogrids interface is evaluated with strength indexes of direct shear experiment. According to the FEM calculation results, the total strain $\gamma_{S}$ can reflect the location of sliding surface. The horizontal coordinates $x_{i j}$ of element nodes corresponding to the peak value of deviant strain in each section where the geogrids locate can also be obtained, among which $i$ means the section where the layer $i$ locates; $j$ means the element node $j$ in the layer $i$. This element node is taken as the cut-off point between shear section and tensile section, as shown in Figure 5. The interface strength of geogrids is adjusted according the following principles:

1) When $x>x_{i p}$ the strength indexes can be obtained through tensile experiments of geogrids;

2) When $x<x_{i j}$ the strength indexes can be obtained through direct shear experiments of geogrids; 
Table 1. Suggested values of geogrids interface strength from different countries' codes.

\begin{tabular}{|c|c|c|c|c|c|c|c|}
\hline Countries & \multicolumn{2}{|c|}{ China } & \multirow{2}{*}{$\begin{array}{c}\text { Germany } \\
\text { Institute of soil } \\
\text { mechanics and } \\
\text { geotechnical } \\
\text { engineering } \\
\text { (EBGEO, 1997) }\end{array}$} & \multirow{2}{*}{$\begin{array}{c}\text { Canada } \\
\text { Canadian } \\
\text { geotechnical } \\
\text { Society } \\
(1992)\end{array}$} & \multirow{2}{*}{$\begin{array}{c}\text { Japan } \\
\text { Public } \\
\text { Research } \\
\text { Center } \\
(2000)\end{array}$} & \multicolumn{2}{|c|}{ America } \\
\hline $\begin{array}{c}\text { Codes or } \\
\text { institutions }\end{array}$ & $\begin{array}{c}\text { Technical } \\
\text { specification for } \\
\text { application of } \\
\text { geosynthetics in } \\
\text { highway } \\
\text { (JGT/T D32-2012) }\end{array}$ & $\begin{array}{l}\text { Standard for } \\
\text { applications of } \\
\text { geosynthetics in } \\
\text { hydro-power } \\
\text { engineering } \\
\text { (SL/T 225-98) }\end{array}$ & & & & $\begin{array}{l}\text { AASHTO Federal } \\
\text { Highway } \\
\text { Administration } \\
\text { (FHWA, 2001) }\end{array}$ & $\begin{array}{l}\text { The National } \\
\text { Association of } \\
\text { Concrete } \\
\text { Masonry } \\
\text { (NCMA, 2009) }\end{array}$ \\
\hline $\begin{array}{c}\text { Interfaces } \\
\text { parameter } \\
\left(\tan \varphi_{G S} / \tan \varphi_{S}\right)\end{array}$ & 0.9 & 0.8 & 0.5 & $\begin{array}{c}\text { Pullout: } \\
0.5 \text { - 0.7; } \\
\text { direct shear: } \\
2 / 3\end{array}$ & 1.0 & $\begin{array}{c}\text { Pullout: } 0.8 \\
\text { direct shear: } \\
2 / 3\end{array}$ & 0.65 \\
\hline
\end{tabular}

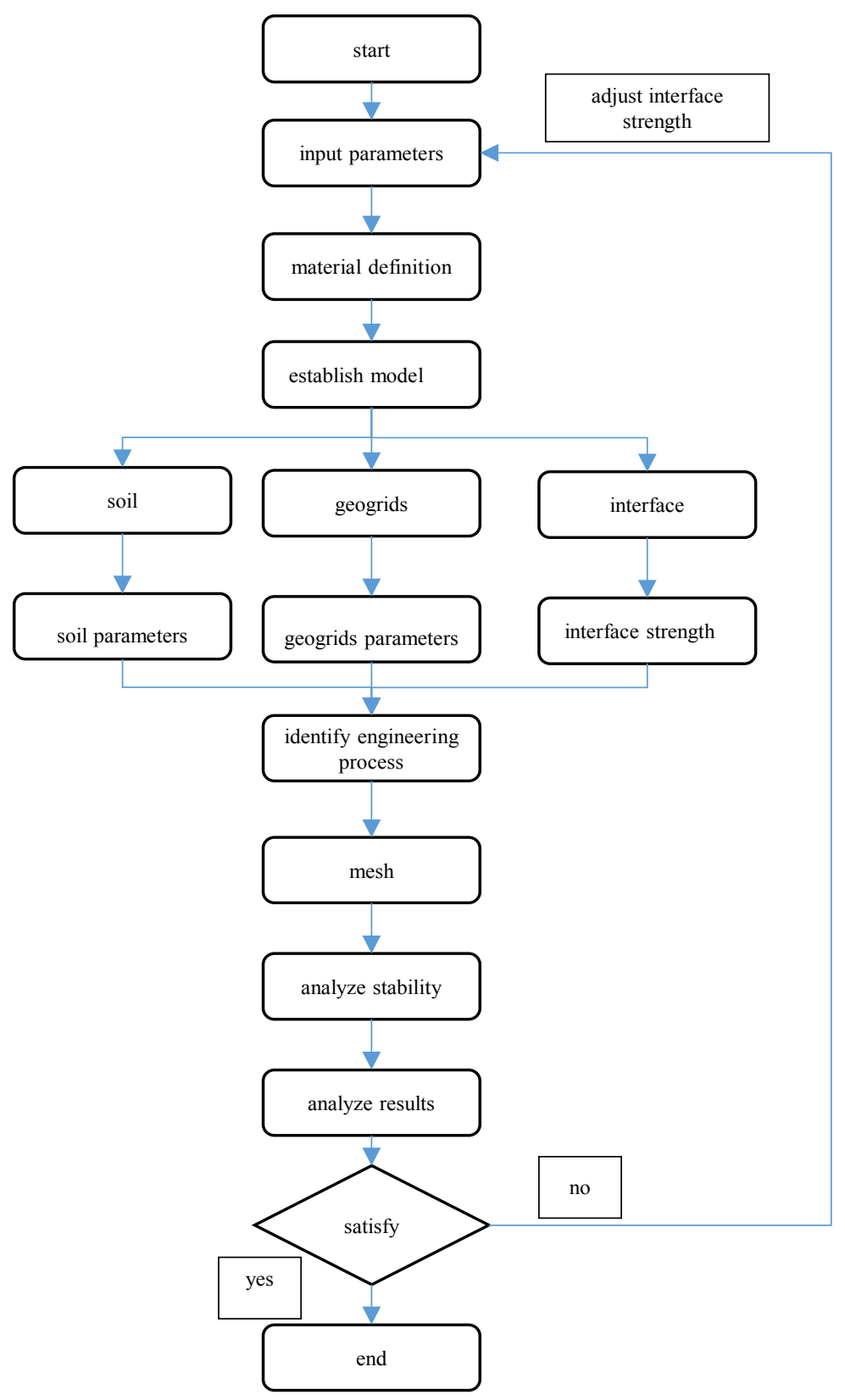

Figure 4. Process of iterative analysis on the stability of reinforcement structure. 


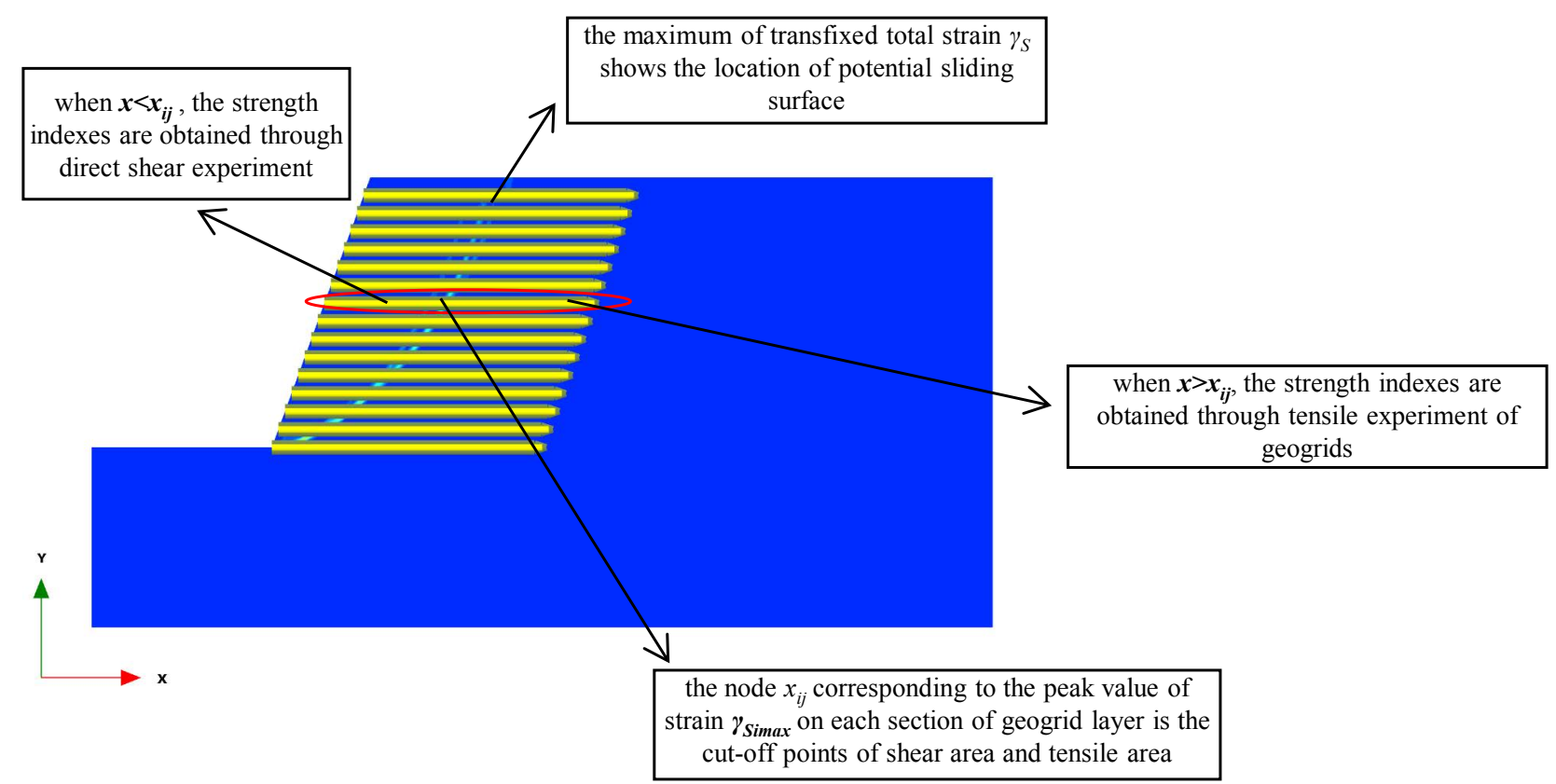

Figure 5. Adjustment of interface strength for the geogrids.

3) When $x=x_{i j}$ the node on the interface is jump point, it should be handled by the program PLAXIS.

Where, $x$ is the horizontal coordinates of the element node.

The stability analysis is conducted again after adjusting the interface strength of geogrids. The analyzed location of potential sliding surface and interface strength of geogrids are taken as the model for the following stability analysis of reinforcement structure. So the iterative analysis is formed till the the stress state of geogrids interface and the unstable failure mode of reinforced structure are identical so the iterative analysis of stability can be completed. At the same time, the controlling standard of convergence in the iterative calculation is that the inaccuracy of stability safety factor through the stability analysis is within $3 \%$.

\section{Calculation Examples}

Taking a reinforced soil slope with single step as an example, the slope angle is $70^{\circ}$ as shown in Figure 6. In the analytic model, the inner friction angle of filling soil $\varphi=25^{\circ}$, cohesion $c=12 \mathrm{kPa}$ and the gravity $\gamma=20 \mathrm{kN} / \mathrm{m}^{3}$; for the foundation soil, the inner friction angle $\varphi=41^{\circ}$, the cohesion $c=120 \mathrm{kPa}$ and the gravity $\gamma=20 \mathrm{kN} / \mathrm{m}$. According to the friction ratio in the Technical Specification for Application of Geosynthetics in Highway (JGT/T D32-2012), the interface friction ratio is $K=\tan \varphi_{G S} d \tan \varphi_{S}$, where $\varphi_{G S}$ is the interface friction angle and $\varphi_{S}$ is the inner friction angle of filling soil. The friction ratio in the direct shear experiment is 0.8 and that from the tensile experiment is 1.2. So the index of direct shear strength for the geogrids interface is $c=9.6 \mathrm{kPa}$ and $\varphi=20.46^{\circ}$. The index of tensile strength is $c=13.2 \mathrm{kPa}$ and $\varphi=27.16^{\circ}$. The length of geogrids is $9 \mathrm{~m}$, the tensile stiffness in the axial direction is $200 \mathrm{kN} / \mathrm{m}$ and the vertical intervals between geogrids is $60 \mathrm{~cm}$. 

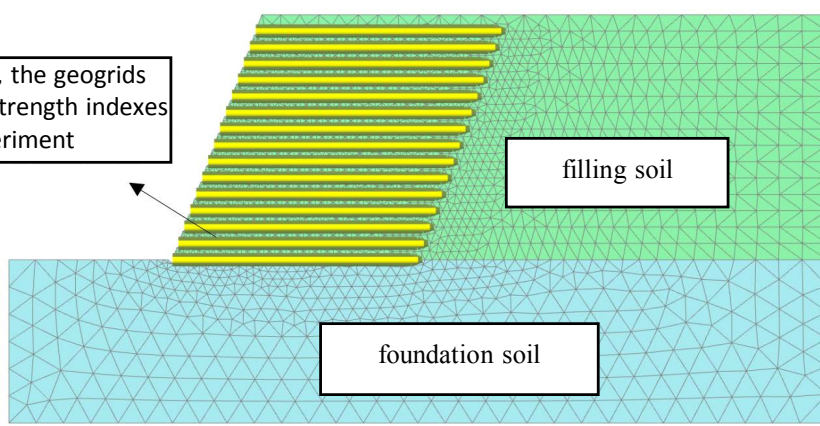

Figure 6. FEM model (initial condition, first iterative calculation).

Under the initial condition, the stability safety factor for the reinforced soil slope is 1.267 and the location of potential sliding surface can be shown in Figure 7 through total strain nephogram.

According to the location of sliding surface under initial condition and the strain climax, the cut-off point between shear area and tensile area of geogrids materials in each layer can be judged. The direct shear strength index of the interface is adopted for geogrids interface in shear area and the tensile strength index is adopted for geogrids interface in the tensile area. So, the FEM model of the next iterative stability analysis for the adjusted interface parameters can be obtained, as shown in Figure 8.

The stability safety factor for the reinforced soil slope after the second stability analysis is 1.325 and the potential sliding surface through the total strain nephogram is shown in Figure 9.

After five times of iterative calculation, the analytic results for the reinforced soil slope is shown in Table 2, where inaccuracy between the safety factor after the forth calculation 1.489 and that after the fifth calculation 1.494 is less than $3 \%$. So, the iterative calculation has been completed, the location of the final potential sliding surface is shown in Figure 10 and the layout of geogrids shear area and tensile are displayed in Figure 11. It can be found in Figure 10 and Figure 11 that the interface characters of geogrids after iterative analysis are identical with its interaction with soil, the geogrids interface inside the sliding surface has shear property and that outside the sliding surface has the tensile property.

\section{Conclusion}

While conducting numerical analysis to study the stability of reinforced soil slope with geogrids, the reasonable basis is insufficient whether to choose the strength index under shear condition or tensile condition for the geogrids interface. The paper studies the relationship between the potential sliding surface when unstable failure happens and the stress state of geogrids interface. It can be found through researches that geogrids interface exerts only shear function or only tensile function, or sometimes both of the mixed functions. So it is limited to adapt the same interface strength indexes, or only considering the shear 


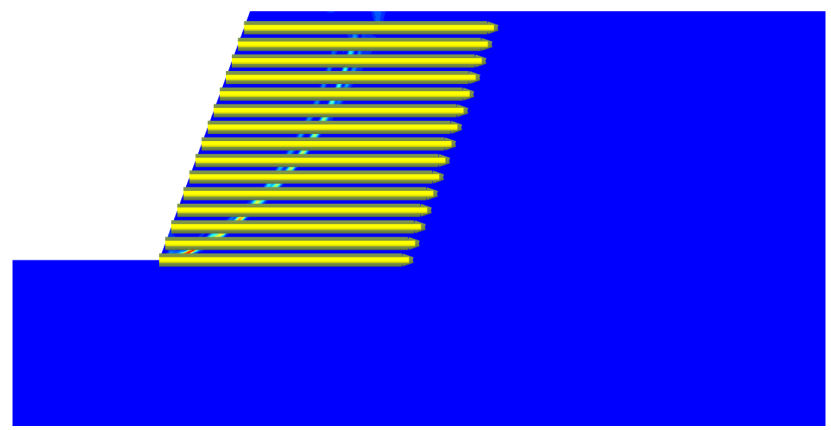

Figure 7. Location of potential sliding surface analyzed under the initial situation (first iterative calculation).

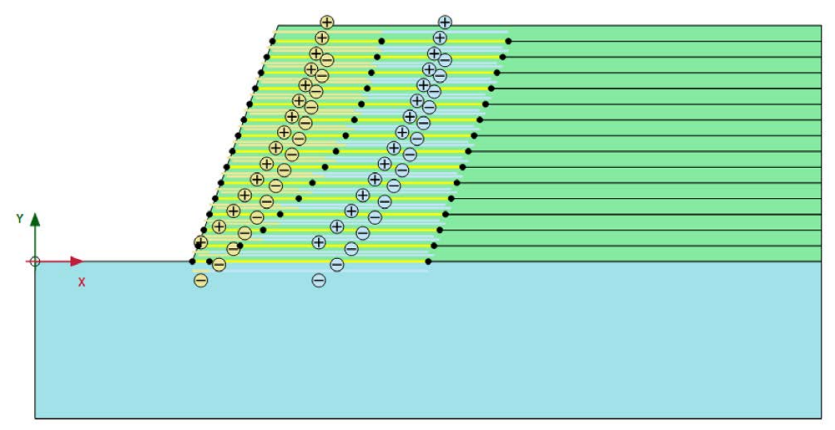

Figure 8. FEM calculation model after adjusting the interface parameters (second iterative calculation).

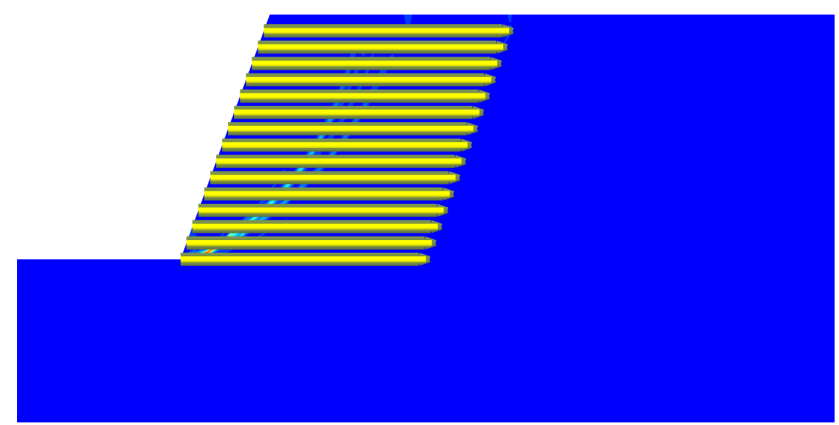

Figure 9. Location of the potential sliding surface analyzed through the second iterative calculation.

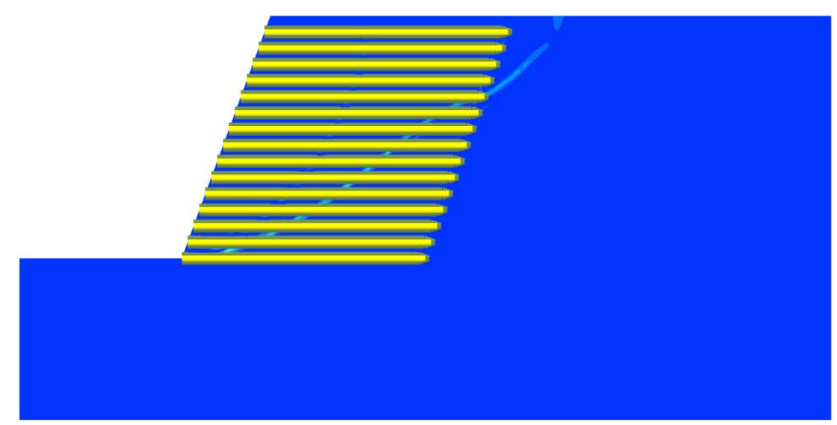

Figure 10. Location of the potential sliding surface analyzed through the fifth iterative calculation. 


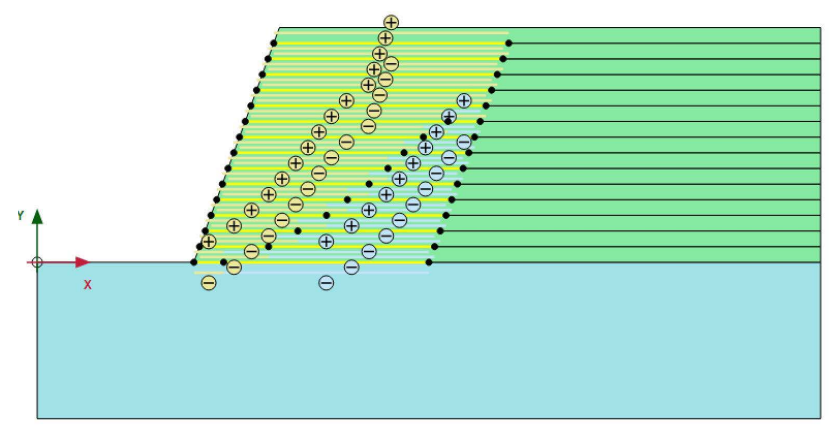

Figure 11. Layout of shear area and tensile area of geogrids after iterative calculations.

Table 2. Iterative calculation results of stability.

\begin{tabular}{cc}
\hline Number of Iterations & stability safety factor \\
\hline One & 1.267 \\
Two & 1.325 \\
Three & 1.408 \\
Four & 1.489 \\
Five & 1.494
\end{tabular}

function or tensile function in the stability analysis, which does not conform to the practical stress state of geogrids. The paper puts forward to adjust the interface indexes of geogrids based on the situation of potential sliding surface when unstable failure happens, so as to form the iterative analysis till the interface characters are the same with the unstable failure mode of the whole structure. This method can reflect the real stress state of geogrids to assure the reasonableness of the analytic results.

\section{Acknowledgements}

The study is supported by the Chongqing basic and leading researching project foundation (cstc2016jcyjys00001).

\section{References}

[1] Yang, G.Q. (2010) The Theories and Application of Reinforced Structure of Geo-Grid. Science Press, Beijing.

[2] Leshchinsky, D. and Han, J. (2004) Geosynthetic Reinforced Multitiered Walls. Journal of Geotechnical and Geoenvironmental Engineering, ASCE, 130, 1225-1235. https://doi.org/10.1061/(ASCE)1090-0241(2004)130:12(1225)

[3] Robert, K.M. and Song, T.-Y. (2001) Geosynthetic Reinforced Segmental Retaining Walls. Geotextiles and Geomembranes, 19, 359-386. https://doi.org/10.1016/S0266-1144(01)00012-7

[4] Onur, M.I., Tuncan, M. and Bertan, B.E. (2016) Behavior of Soil Reinforcements in Slopes. Procedia Engineering, 143, 486-489. https://doi.org/10.1016/j.proeng.2016.06.061 
[5] Wei, H.W., Yu, Z.H. and Zou, Y.S. (2006) Performances of Shear zones and Failure Modes in Geosynthetic Reinfoeced Slopes. Engineering Mechanics, 23, 104-108.

[6] Mosallanezhad, M., Sadat Taghavi, S.H. and Hataf, N. (2016) Experimental and Numerical Studies of the Performance of the New Reinforcement System Under Pull-Out Conditions. Geotextiles and Geomembranes, 44, 70-80.

https://doi.org/10.1016/j.geotexmem.2015.07.006

[7] Balakrichnan, S. and Viswanadham, B.V.S. (2016) Evaluation of Tensile Load-Strain Characteristics of Geogrids through In-Soil Tensile Tests. Geotextiles and Geomembranes, 36, 1-10.

[8] Abdi, M.R. and Zandieh, A.R. (2014) Experimental and Numerical Analysis of Large Scale Pull Out Tests Conducted on Clay Reinforced with Geogrids Encapsulated with Coarse Material. Geotextiles and Geomembranes, 42, 494-504. https://doi.org/10.1016/j.geotexmem.2014.07.008

[9] Cai, J.-T. (2015) Pull-Out Test on Interface Behavior between Expansive Soils and Geogrids. Rock and Soil Mechanics, 36, 203-307.

[10] Li, G.-X. (2013) Some Problems in Design of Geosynthetic-Reinforced Soil Structures. Chinese Journal of Geotechnical Engineering, 35, 605-610.

[11] Zornberg, J.G. and Leshchinsky, D. (2001) Comparison of International Design Criteria for Geosynthetic-Reinforced Soil Structure. Ochiai, H., Ed., Geosynthetics and Earth Reinforcement, ISSMGE-TC9 (1998-2001). 